\title{
Aplikasi Presensi Dosen Mengajar Menggunakan Global Positioning System (GPS) Berbasis Android
}

\author{
Wisnu Wendanto*1, Agung Nugroho ${ }^{2}$, Yeni Nur Irsalina ${ }^{3}$ \\ ${ }^{1}$ Program Studi Sistem Komputer ${ }^{2,3}$ Program Studi Sistem Informasi; \\ ${ }^{123}$ STMIK AUB Surakarta, Indonesia \\ e-mail: *1wisnu.wendanto@stmik-aub.ac.id, ${ }^{2}$ agung_new@stmik-aub.ac.id, \\ 3yeni_nur@gmail.com
}

\begin{abstract}
Abstrak
Global Positioning System (GPS) merupakan suatu sistem yang dapat digunakan untuk menentukan letak di permukaan bumi. Sistem tersebut bekerja dengan bantuan penyelarasan sinyal satelit. GPS adalah sistem satelit navigasi yang paling populer dan banyak diaplikasikan di dunia. Baik di darat, laut, udara, maupun angkasa. Sekarang ini, GPS menjadi salah satu fitur yang wajib ada pada ponsel pintar. Keberadaan fitur GPS ini diakui memberi kemudahan seperti: kecepatan arah, menentukan jarak, dan juga posisi objek secara berkala. Penelitian ini membahas aplikasi presensi berbasis android menggunakan GPS. Hasil yang dicapai adalah untuk kontrol presensi Dosen mengajar secara mobile. Kedisiplinan Dosen dalam hal mematuhi jadwal mengajar merupakan salah satu bagian kecil pada proses perkuliahan, selain kualitas mengajar Dosen itu sendiri. Faktor ini dapat diukur dengan akumulasi tingkat kehadiran Dosen per bulan, per semester atau periode-periode lain yang dibutuhkan. Tingkat kehadiran Dosen dapat dilakukan berdasarkan presensi. Presensi Dosen harus dilakukan secara tepat. Sehingga mudah dan sederhana di sisi pengguna dan informatif di sisi manajemen atau pengambil keputusan. Begitu pentingnya presensi Dosen mengajar, sehingga dapat digunakan untuk memonitoring dan mengevaluasi kinerja Dosen. Oleh karena itu, dibutuhkan mekanisme presensi Dosen yang tepat. Teknologi Global Positioning System (GPS) merupakan teknologi pendukung aplikasi presensi pada perguruan tinggi.
\end{abstract}

Kata kunci: Aplikasi, Presensi, Dosen, Global Positioning System,Smartphone, Android

\section{PENDAHULUAN}

Menurut Kamus Besar Bahasa Indonesia (2008), presensi adalah kehadiran. Sehingga presensi bisa diartikan sebagai suatu kegiatan yang dilakukan oleh suatu organisasi, instansi, maupun perusahaan sebagai standar untuk menilai kedisiplinan anggotanya berdasarkan kuantitas kehadiran.Presensi Dosen memegang peranan penting dalam setiap proses kegiatan belajar mengajar. Dimana presensi merupakan salah satu penunjang yang dapat mendukung atau memotivasi setiap kegiatan yang dilakukan di dalamnya. Disamping itu, presensi dapat juga diartikan sebagai informasi tentang bagaimana kedisiplinan Dosen pengampu yang bersangkutan. Penting adanya bagi Pimpinan untuk mengetahui dan memantau kehadiran Dosen pengampu di kampus secara real-time.

Perkembangan teknologi yang semakin pesat saat ini telah membuat banyak perubahan dalam gaya hidup masyarakat. Salah satu perubahannya adalah banyaknya penggunaan smartphone, terutama smartphone yang berbasis android untuk kehidupan sehari-hari. Penggunaan teknologi presensi berbasis android dapat dikatakan lebih baik karena adanya kemudahan dalam pengaksesan dan pengambilan informasi. Peningkatan terhadap mutu pengajar disesuaikan dengan perkembangan teknologi saat ini.

Received May 3, 2018; Revised May 25, 2018; Accepted June 10, 2018 
Dalam kegiatan akademik STMIK AUB Surakarta, pendataan kehadiran Dosen mengajar adalah hal yang rutin dilakukan dengan pengisianlembar kehadiran disetiap pertemuan. Hal itu masih timbul beberapa permasalahan yaitu banyaknya data yang dimasukkan dan harus mengulanginya, yang dapat terjadi kesalahan ataupun data dapat dimanipulasi. Terdapat permasalahan ketika ada Dosen yang tidak hadir pada saat mengajar tanpa keterangan yang jelas, yang dapat mengganggu kegiatan perkuliahan. Keterbatasan informasi yang tersimpan dalam menampilkan kehadiran Dosen mengajar secara real-time menuntut adanya suatu inovasi.

Berdasarkan permasalahan yang ada di STMIK AUB Surakarta, maka mendorong Penulis untuk membuat sebuah Aplikasi Presensi DosenMengajar Menggunakan Global Positioning System (GPS)Berbasis AndroidPadaSTMIK AUB Surakarta dengan pemberitahuan secara real-time mengenai laporan kehadiran Dosen pengampu dan jadwal mata kuliah. Dosen pengampu juga dapat memberitahukan jika akan melakukan izin beserta dengan alasannya. Dengan teknologi GPS lebih praktis, user tidak perlu menggunakan perangkat tambahan dan guna kelancaran presensi Dosen dengan mobilitas yang tinggi. Kaprogdi dapat melihat aktivitasDosenmengajar yang dapat diakses dan ditampilkan melalui layar smartphone. Teknologi GPS melakukan deteksi terhadap lokasi Dosen berada, maka sistem akan membaca dan mengidentifikasi lokasi sesuai dengan titik koordinat lokasi kampus STMIK AUB Surakarta, yaitu di halaman kampus STMIK AUB Surakarta. Deteksi inilah yang akan dibaca oleh sistem dan memberi penanda bahwa Dosen telah memenuhi kehadiran dengan jangkauan akurat sampai dengan radius kurang dari 25 meter dari titik pusat. Sistem ini bertujuan untuk meningkatkan kedisiplinan Dosen dan kelancaran kegiatan perkuliahan. Agar Kaprogdi dapat mengetahui dan memproses Dosen yang sering tidak hadir supaya Kaprogdi dapat mencarikan pengganti Dosen yang lain, agar tidak mengganggu kegiatan perkuliahan yang ada.

\section{METODE PENELITIAN}

\subsection{Analisis Kebutuhan Sistem}

Analisis yang dimaksud adalah membangun aplikasi dengan tujuan untuk mengetahui dan memahami kebutuhan sistem baru yang terdapat di STMIK AUB Surakarta.

\subsection{Kebutuhan Perangkat Keras (Hardware)}

Spesifikasi minimum perangkat keras (hardware) yang dibutuhkan untuk membangun sistem ini adalahsmartphone android dengan spesifikasi sebagai berikut:

Tabel 1 Spesifikasi minimum perangkat keras (hardware)

\begin{tabular}{|c|l|l|}
\hline No & \multicolumn{1}{|c|}{ Jenis } & \multicolumn{1}{c|}{ Kebutuhan } \\
\hline 1 & RAM & $1 \mathrm{~GB}$ \\
\hline 2 & Memori Internal & $8 \mathrm{~GB}$ \\
\hline 3 & Koneksi & $3 \mathrm{G}$ \\
\hline
\end{tabular}

2.3 Kebutuhan Perangkat Lunak

Perangkat lunak (software)yang dibutuhkan untuk membangun sistem ini adalah sebagai berikut:

Tabel 2 Kebutuhan perangkat lunak (software)

\begin{tabular}{|c|l|l|}
\hline No & \multicolumn{1}{|c|}{ Perangkat Lunak } & \multicolumn{1}{c|}{ Keterangan } \\
\hline 1 & Sistem Operasi & Jelly bean \\
\hline 2 & Database & MySQL \\
\hline 3 & Editor & Notepad ++ \\
\hline 4 & Web Server & XAMPP \\
\hline
\end{tabular}

2.4 Kebutuhan Informasi

Informasi yang yang disajikan aplikasi presensi ini berupa pengolahan data presensi, adapun data yang didapat antara lain:

a. Data Dosen

b. Data Mata Kuliah

Aplikasi Presensi Dosen Mengajar Menggunakan Global Positioning System (GPS) Berbasis 
c. Jadwal Kuliah

2.5 Kebutuhan Pengguna (User)

Kebutuhan pengguna yang nantinya akan mengoperasikan program yang sudah dibuat yaitu Administrator, Kaprogdi dan Dosen. Administrator adalah staf STMIK AUB Surakarta yang bertugas menginputkan data Dosen, data mata kuliah, dan jadwal kuliah. Kaprogdi merupakan pengguna untuk melihat data presensi yang dilihat oleh sistem, serta jadwal mata kuliah. Dosen merupakan pengguna GPS untuk proses presensi setiap akan memulai kegiatan mengajar .

\section{HASIL DAN PEMBAHASAN}

Tujuan pembahasan ini adalah untuk mengetahui apakah program yang dibuat sudah bekerja seperti yang diharapkan atau belum. Berikut adalah proses pembahasan interface atau antarmuka program:

a. Login Admin

1. Halaman LoginAdmin

Masukkan username dan password Admin. Klik radio button, lalu pilih Admin. Lalu klik Login untuk masuk ke halaman.

2. Halaman Utama Admin

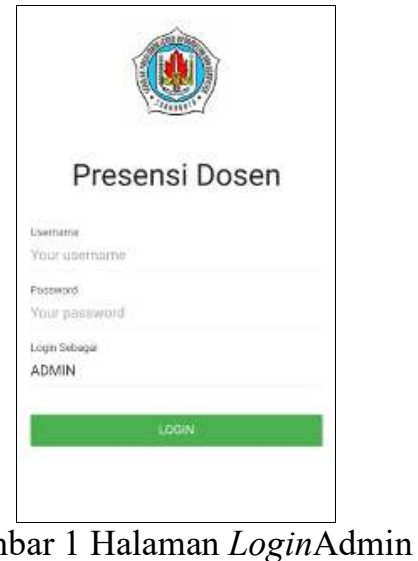

Halaman utama Admin terdapat empat menu yaitu menu Mata Kuliah, menu Dosen, menu Jadwal, dan menu Logout.

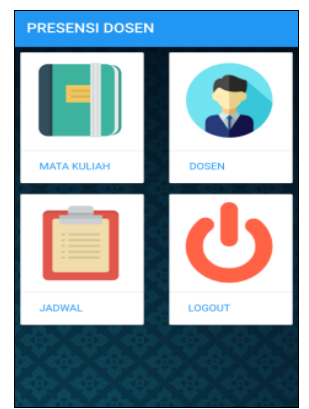

3. Halaman Mata Kuliah

Gambar 2 Halaman Utama Admin

Halaman Mata Kuliah digunakan Admin untukmelihat daftar mata kuliah. Terdapat fungsi Search untuk pencarian, Add untuk tambah data, icon Pencil untuk edit data, icon Trash untuk hapus data. Geser layar ke kiri untuk melihat data lengkap berisi: kode mata kuliah, nama mata kuliah, SKS, dan semester.

GO INFOTECH: JURNAL ILMIAH STMIK AUB Vol. 24, No. 1, Juni 2018 : $54-63$ 


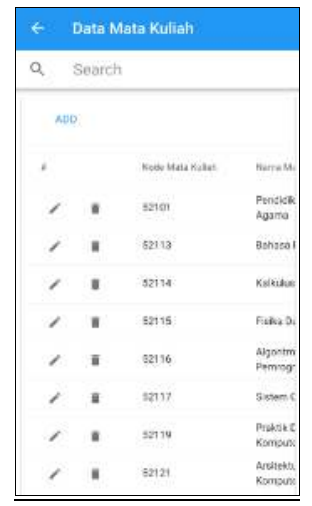

Gambar 3 Halaman Mata Kuliah

4. Halaman Tambah DataMata Kuliah

Halaman tambah data mata kuliah digunakan Admin untuk menambahkan data matakuliah. Data yang harus dimasukkan antara lain: kode mata kuliah, nama mata kuliah, jumlah SKS, dan semester. Jika data sudah lengkap diisi klik Button Simpan untuk menyimpan dan Tutup untuk mengakhiri halaman.

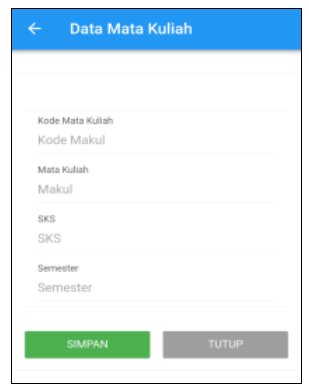

5. Halaman Dosen

Gambar 4 Halaman Tambah Data Mata Kuliah

Terdapat fungsi Search untuk pencarian, Add untuk tambah data, icon Pencil untuk edit data, icon Trash untuk hapus data. Geser layar ke kiri untuk melihat tampilan data lengkap berisi:NIPY Dosen, nama Dosen, jabatan, golongan, no. HP, dan alamat.

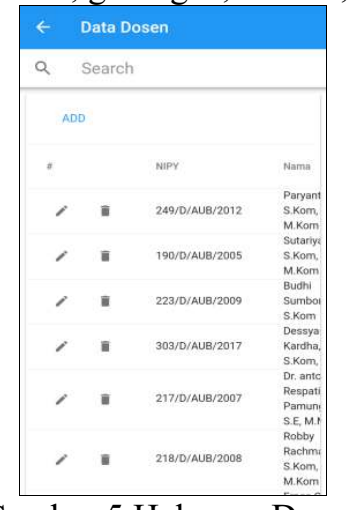

6. Halaman Tambah Data Dosen

Gambar 5 Halaman Dosen

Halaman tambah data Dosen digunakan Admin untuk menambahkan data Dosen yang aktif mengajar di STMIK AUB Surakarta. Data Dosen yang harus dimasukkan antara lain: NIPY Dosen, nama Dosen, jabatan, golongan, no. HP, dan alamat. Jika data sudah lengkap diisi klik Button Simpan untuk menyimpan dan Tutup untuk mengakhiri halaman.

Aplikasi Presensi Dosen Mengajar Menggunakan Global Positioning System (GPS) Berbasis 


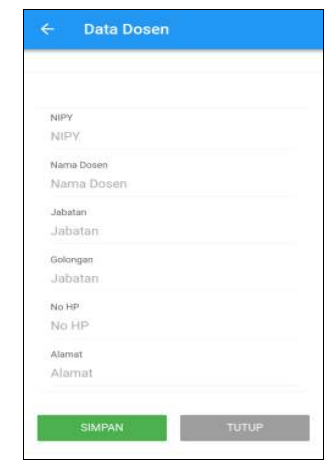

7. Halaman Jadwal

\section{Gambar 6 Halaman Tambah Data Dosen}

Terdapat fungsi Search untuk pencarian, Add untuk tambah data, icon Pencil untuk edit data, icon Trash untuk hapus data. Geser layar ke kiri untuk melihat tampilan data lengkap berisi:NIPY Dosen, nama Dosen, mata kuliah, waktu mulai, waktu selesai, hari, ruang.

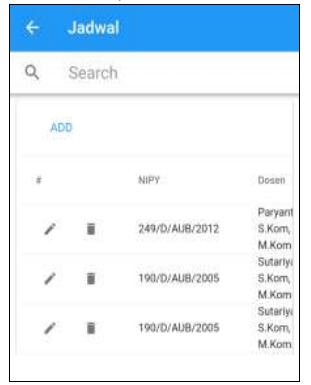

Gambar 7 Halaman Jadwal

8. Halaman Tambah Jadwal

Halaman tambah data jadwal digunakan Admin untuk menambahkan data jadwal Dosenmengajar yang ada di STMIK AUB Surakarta. Data jadwal yang harus dimasukkan antara lain: mata kuliah, nama Dosen yang mengampu mata kuliah, mulai untuk waktu mulai pertemuan, selesai untuk waktu selesai pertemuan, hari, ruang kelas, tahun ajaran, semester, dan kelas. Jika data sudah lengkap diisi klik Button Simpan untuk menyimpan dan Tutup untuk mengakhiri halaman.

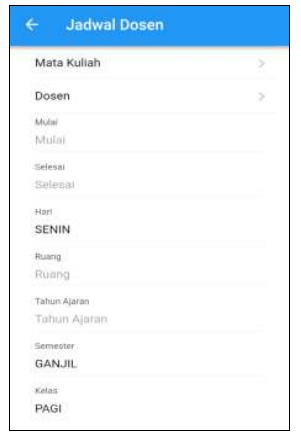

Gambar 8 Halaman Tambah Jadwal

b. Login Dosen

1. Halaman Login Dosen

Dosen terlebih dahulu login menggunakan username dan password sesuai NIPY masing-masing sebagai identitas yang sudah didaftarkan Admin. Terdapat radio button pilihan Program Studi yaitu Sistem Informasi, Sistem Komputer, dan Teknik Komputer untuk memilih kelas dimana Dosen akan mengajar. Lalu klik Login untuk masuk ke halaman utama.

GO INFOTECH: JURNAL ILMIAH STMIK AUB Vol. 24, No. 1, Juni 2018 : $54-63$ 


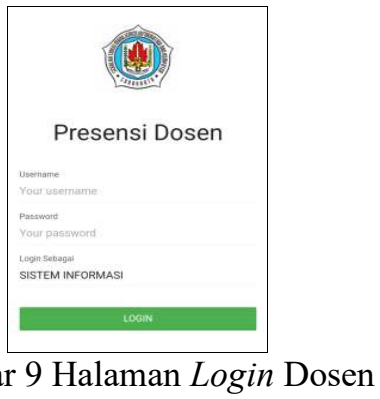

2. Halaman Utama Dosen

Gambar 9 Halaman Login Dosen dan Logout.

Halaman utama Dosen menampilkan empat menu yaitu menu Presensi, Izin, Jadwal,

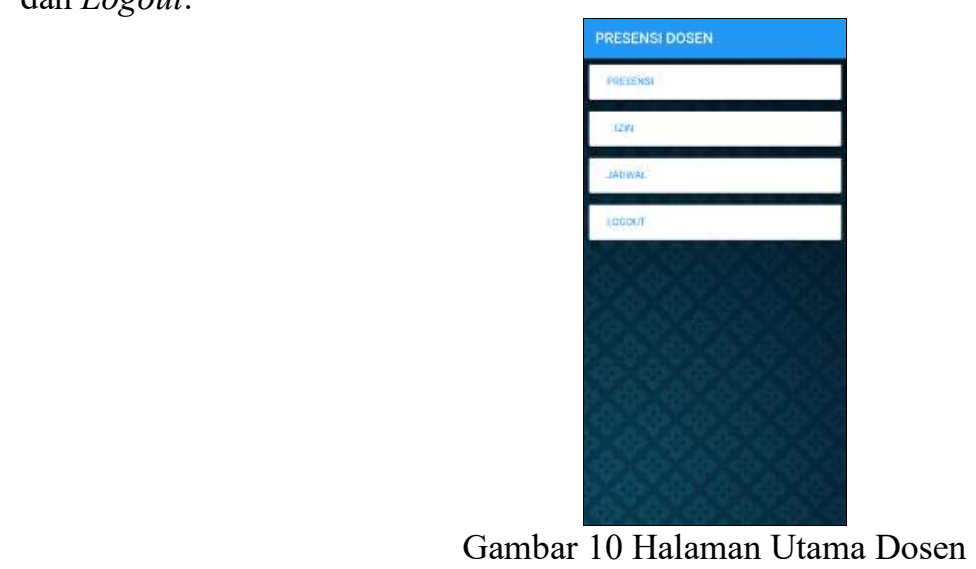

3. Halaman Menu Presensi

Halaman Presensi digunakan untuk membantu Dosen melakukan presensi. Presensi dilakukan dengan GPS, apabila lokasi terdeteksi dalam jangkauan 25 meter dari pusat koordinat yaitu tepat sebelah selatan ruang Laboratorium 1 kampus STMIK AUB Surakarta maka presensi diperbolehkan.

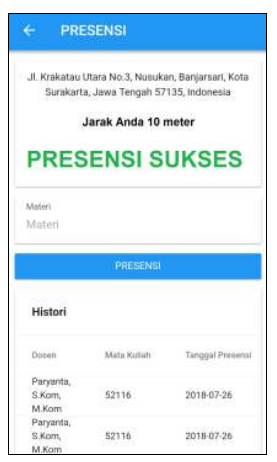

Gambar 11 Halaman Presensi Sukses

4. Halaman Menu Izin

Dosen yang berhalangan hadir dapat menyampaikan izin dengan memilih menu Izin. Setelah mengisi data yang diperlukan, Admin akan menerima data izin dari Dosen untuk dapat diketahui ke pihak terkait. Dosen dapat menggunakan fitur izin dalam waktu 30 menit sebelum jadwal mengajar masing-masing. 


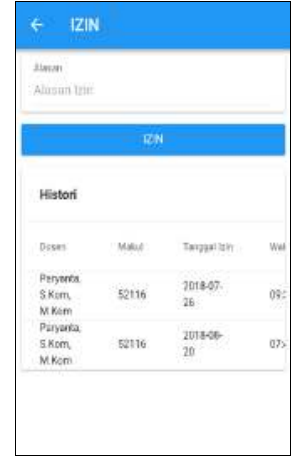

5. Halaman Menu Jadwal

Gambar 12 Halaman Menu Izin

Halaman ini menampilkan jadwal Dosen mengajar (yang mempunyai akun). Digunakan Dosen untuk melihat jadwal, agar tepat waktu dalam presensi dan lebih aktif dalam mengajar.

c. Login Kaprogdi

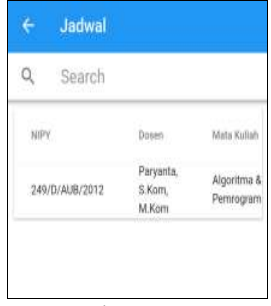

Gambar 13 Halaman Menu Jadwal

1. Halaman Login Kaprogdi

Kaprogdi terlebih dahulu login menggunakan username dan password sesuai yang sudah ditentukan oleh masing-masing sebagai identitas yang tidak akan disalah gunakan.

2. Halaman Utama Kaprogdi

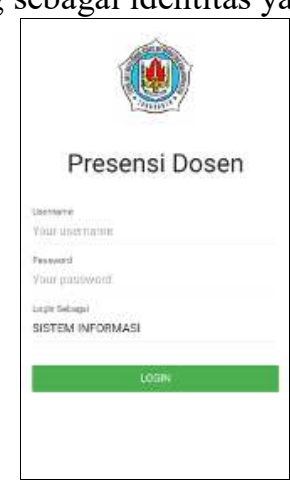

Gambar 14 Halaman Login Kaprogdi

Halaman utama Kaprogdi menampilkan tiga menu yaitu menu Laporan Presensi, Jadwal, dan Logout.

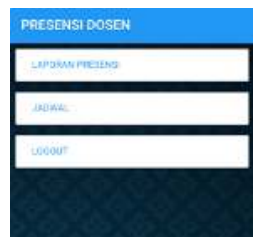

Gambar 15 Halaman Utama Kaprogdi

3. Halaman Menu Laporan Presensi

Halaman ini untuk mengunduh serta melihat histori Dosen yang sudah melakukan presensi. Untuk mengunduh Kaprogdi hanya perlu klik pilih bulan dan pilih Progdi, lalu klik

GO INFOTECH: JURNAL ILMIAH STMIK AUB Vol. 24, No. 1, Juni 2018 : $54-63$ 
button Unduh PDF untuk proses mengunduh. File yang sudah diunduh akan tersimpan di folder berkas pada smartphone.

4. Halaman Menu Jadwal

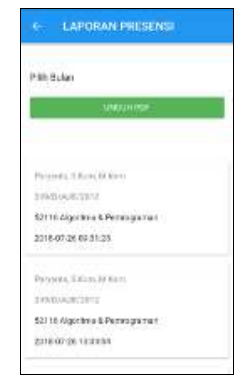

Gambar 16 Halaman Menu Laporan Presensi

Halaman ini menampilkan seluruh jadwal Dosen mengajar yang sudah diinputkan oleh Admin. Digunakan Kaprogdi untuk melihat jadwal Dosen ataupun untuk meneliti, menyamakan dengan laporan presensi yang ada.

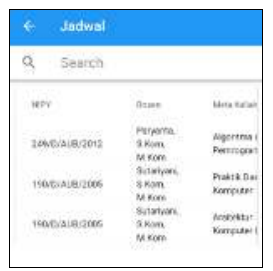

Gambar 17 Halaman Menu Jadwal

Dalam pembahasan sistem baru, penulis menggunakan analisis PIECESyang terdiri dari Performance, Information, Control, Efficiency dan Service. Sebagai alat ukur untuk membandingkan antara sistem lama dengan sistem yang baru, yaitu sebagai berikut:

Tabel 3 Pembahasan sistem baru

\begin{tabular}{|l|l|l|}
\hline \multicolumn{1}{|c|}{ Analisa } & \multicolumn{1}{|c|}{ Hasil Analisis Sistem Lama } & \multicolumn{1}{c|}{ Hasil Analisis Sistem Baru } \\
\hline $\begin{array}{l}\text { Perfomance } \\
\text { (Kinerja) }\end{array}$ & $\begin{array}{l}\text { Sistem yang lama masih } \\
\text { menggunakan form presensi Dosen } \\
\text { mengajar di lembaran kertas yang } \\
\text { memiliki kinerja kurang maksimal } \\
\text { karena lembar presensi yang terbuat } \\
\text { dari kertas dapat kotor, basah, } \\
\text { tercecer ataupun hilang. }\end{array}$ & $\begin{array}{l}\text { Sistem yang baru berbasis android, } \\
\text { dengan menggunakan teknologi GPS. } \\
\text { Dosen hanya memerlukan perangkat } \\
\text { smartphone untuk mengakses lokasi } \\
\text { dengan GPS, tidak perlu perangkat } \\
\text { tambahan lagi. Sehingga } \\
\text { menguntungkan untuk mobilitas. }\end{array}$ \\
\hline $\begin{array}{l}\text { Information } \\
\text { (Informasi) }\end{array}$ & $\begin{array}{l}\text { Informasi yang berlakuhanya satu } \\
\text { arah, Dosen tidak dapat melihat } \\
\text { keaktifannya dalam mengajar } \\
\text { secara real-time. }\end{array}$ & $\begin{array}{l}\text { Informasi yang dihasilkansangat } \\
\text { memudahkan Dosen dalam melihat } \\
\text { keaktifan karena sudah ditampilkan } \\
\text { pada histori presensi dan data } \\
\text { tersimpan di database. }\end{array}$ \\
\hline $\begin{array}{l}\text { Economy } \\
\text { (Ekonomi) }\end{array}$ & $\begin{array}{l}\text { Print out lembar presensi Dosen } \\
\text { mengajar yang harus mengeluarkan } \\
\text { biaya yang tidak sedikit } \\
\text { danmengakibatkan pemborosan } \\
\text { untuk ketersediaan lembar presensi } \\
\text { setiap minggu. }\end{array}$ & $\begin{array}{l}\text { Biaya yang dibutuhkan relatifrendah } \\
\text { karena hampir seluruh Dosen memiliki } \\
\text { smartphone, sehingga dapat } \\
\text { menjalankan aplikasi dengan mudah, } \\
\text { tanpa print-out form presensi. }\end{array}$ \\
\hline
\end{tabular}

Aplikasi Presensi Dosen Mengajar Menggunakan Global Positioning System (GPS) Berbasis 


\begin{tabular}{|c|c|c|}
\hline $\begin{array}{l}\text { Control } \\
\text { (Keamanan) }\end{array}$ & $\begin{array}{l}\text { Keamanan kurang karena presensi } \\
\text { dengan lembaran kertas, Dosen } \\
\text { dapat memalsukan data kehadiran } \\
\text { serta datang terlambat karena } \\
\text { minimnya pengawasan. Selain itu } \\
\text { lembar presensi dapat tercecer. }\end{array}$ & $\begin{array}{l}\text { Keamanan lebih terjamin karena } \\
\text { aplikasi berbentuk file apk. Setiap } \\
\text { akun hanya bisa login menggunakan } \\
\text { username dan passwordyang telah } \\
\text { terdaftar oleh Admin, dan presensi } \\
\text { hanya dapat menggunakan teknologi } \\
\text { GPS dengan titik koordinat kampus } \\
\text { STMIK AUB Surakarta. }\end{array}$ \\
\hline $\begin{array}{l}\text { Efficiency } \\
\text { (Efisiensi) }\end{array}$ & $\begin{array}{l}\text { Presensi Dosen mengajar } \\
\text { menggunakan lembar kertas dimana } \\
\text { Dosen mengisi daftar hadir di form } \\
\text { yang sudah disediakan di box file } \\
\text { presensi dan Dosen harus menuju } \\
\text { kesana. Dosen harus mengisi data } \\
\text { berulang-ulang setiap kali akan } \\
\text { mengajar. Lembar presensi hanya } \\
\text { dapat digunakan untuk mencatat } \\
\text { kehadiran Dosen. Sedangkan tidak } \\
\text { terintegrasi dengan jadwal } \\
\text { perkuliahan. }\end{array}$ & $\begin{array}{l}\text { Sistem yang barusudah tidak } \\
\text { menggunakan kertas sebagai media } \\
\text { presensi, sehingga tidak menambah } \\
\text { beban biaya dan pengisian lembar } \\
\text { presensi yang berulang-ulang. Presensi } \\
\text { dapat dilakukan dimana saja dengan } \\
\text { smartphone dan akun masing-masing } \\
\text { user sesuai wilayah jangkauan yang } \\
\text { ditentukan, yaitu berada di area } \\
\text { kampus STMIK AUB Surakarta. }\end{array}$ \\
\hline $\begin{array}{l}\text { Service } \\
\text { (Layanan) }\end{array}$ & $\begin{array}{llr}\text { Untuk menjaga lembar presensi } \\
\text { Dosen mengajar agar maksimal, } \\
\text { pengecekan harus rutin dilakukan } \\
\text { dalam hal kerapian dan } \\
\text { kelengkapannya. Sehingga presensi } \\
\text { menggunakan lembar kertas } \\
\text { membutuhkan pelayanan lebih } \\
\text { untuk menjaga kebersihan dan } \\
\text { ketersediaannya. }\end{array}$ & $\begin{array}{l}\text { Pelayanan yang diberikan pada } \\
\text { aplikasi sangat membantu Dosen, } \\
\text { karena Dosen yang bersangkutan dapat } \\
\text { melihat histori presensi. User juga } \\
\text { dapat melihat jadwal mata kuliah yang } \\
\text { terintegrasi dan mengunduh laporan } \\
\text { presensi dengan mudah. }\end{array}$ \\
\hline
\end{tabular}

\section{KESIMPULAN}

Proses perancangan Aplikasi Presensi Dosen Menggunakan Global Positioning System (GPS) Berbasis Android Pada STMIK AUB Surakarta yang telah dibuat dapat diambil kesimpulan sebagai berikut: Langkah analisa yang diterapkan dengan menganalisa kelemahan sistem terdahulu, menentukan kriteria, membuat diagram alir sistem yang dikembangkan, pemodelan sistem dengan menggunakan metode DFD, membuat rancangan input dan juga output serta membuat desain database. Aplikasi yang dibuat menggunakan Apache Cordova, bahasa pemrograman Java Script dan database MySQL. Teknologi GPS melakukan deteksi terhadap lokasi Dosen berada, maka sistem akan membaca dan mengidentifikasi lokasi sesuai dengan titik koordinat lokasi kampus STMIK AUB Surakarta. Aplikasi Presensi Dosen Menggunakan Global Positioning System (GPS) Berbasis Android Pada STMIK AUB Surakarta dengan pemberitahuan secara real-time mengenai laporan kehadiran Dosen pengampu dan jadwal mata kuliah. Aplikasi ini selain untuk presensi Dosen pengampu,dapat juga untuk memberitahukan jika Dosen akan melakukan izin beserta dengan alasannya. Dengan teknologi GPS lebih praktis, user tidak perlu menggunakan perangkat tambahan dan guna kelancaran presensi Dosendengan mobilitas yang tinggi. Kaprogdi dapat melihat aktivitas Dosen mengajar yang dapat diakses dan ditampilkan melalui layar smartphone.

GO INFOTECH: JURNAL ILMIAH STMIK AUB Vol. 24, No. 1, Juni 2018 : 54 - 63 


\section{SARAN}

Berdasarkan penjelasan yang telah Penulis uraikan sebelumnya, maka untuk penilitian atau Skripsi kedepan, saran yang dapat diberikan untuk pengembangan yang dapat dilakukan pada aplikasi yang dibuat adalah: Aplikasi dapat diintegrasikan dengan teknologi Face Recognition kaitannya verifikasi kemanan dan teknologi Bluetooth untuk jangkauan yang lebih terbatas. Aplikasi dapat ditambahkan untuk penilaian kinerja Dosen.

\section{DAFTAR PUSTAKA}

[1] Anonim. 2016. Buku Pedoman Penyusunan Skripsi. Surakarta: STMIK AUB Surakarta.

[2] Gat. 2015. Integrasi Fingerprint System dengan Real Time Absensi Dosen Berbasis Web. Cogito Smart Journal. ISSN: 2541, Volume 2, Nomor 2, Halaman 135-146. http://www.ejurnal.com/2017/10/integrasi-fingerprint-system-dengan.html?m=1.Diakses pada tanggal 02 Maret 2018.

[3] Hermawan S, Stephanus. 2011. Mudah Membuat Aplikasi Android. Yogyakarta: Andi.

[4] Irawan, dkk. 2015. Presensi Sidik Jari (Fingerprint) Berbasis Web Service. Jurnal Fakultas MIPA Universitas Mulawarnman, Volume 1, Nomor 1. Samarinda. http://fmipa.unmul.ac.id./files/docs/Jurnal-Adi\%20Irawan.pdf.Diakses pada tanggal 02 Juni 2018.

[5] Jogiyanto, H. 2005. Anaisis dan Desain Sistem Informasi. Yogyakarta: Andi Offset.

[6] Kristanto, Andri. 2003. Perancangan Sistem Informasi dan Aplikasinya. Jakarta: Gava Media.

[7] Parlika. Rizky. Dkk. 2014. Sistem Absensi Sidik Jari Terintegrasi Sms Gateway Berbasis Dekstop Menggunakan Visual Basic dan Mysql. Jurnal Informatika. 9 (2): 7. http://eprints.upnjatim.ac.id. Diakses pada tanggal 02 Maret 2018.

[8] Pressman, Roger. 2010. Rekayasa Perangkat Lunak Pedekatan Praktisi. Yogyakarta: Andi.

[9] Ragil, Wukil. 2010. Pedoman Sosialisasi Prosedur Operasi Standar. Jakarta: Mitra Wacana Media.

[10] Saputro, R.D dan Hartanto, A.D. 2013. Perancangan Sistem Informasi Presensi Menggunakan Visual Basic Pada Jogja Fitnes. Jurnal Ilmiah DASI, ISSN: 1411-3201, Volume $\quad 14, \quad$ Nomor $\quad 04, \quad$ Halaman 44-48. http://ojs.amikom.ac.id/index.php/dasi/article/download/143/128/.Diakses pada tanggal 22 Juli 2018.

[11] Sandi, Mulyana. 2014. Bikin Website dengan Aplikasi-aplikasi Gratis Cepat, Mudah \& Murah. Yogyakarta: MediaKom.

[12] Sunyoto, Andi. 2007. Ajax Membangun Web dengan Teknologi Asynchronouse JavaScript dan XML. Yogyakarta: CV. Andi Offset.

[13] Wikipedia Bahasa Indonesia. 2017. Pengertian Aplikasi. http://id.m.wikipedia.org/wiki/Aplikasi. Diakses pada tanggal 01 Juni 2018.

[14] Winardi. 2006. Penentuan Posisi dengan GPS untuk Survey Terumbu Karang. Puslit Oseanografi-LIPI. http://www.coremap.or.id/download/GPS.pdf. Diakses pada tanggal 01 Juni 2018. 